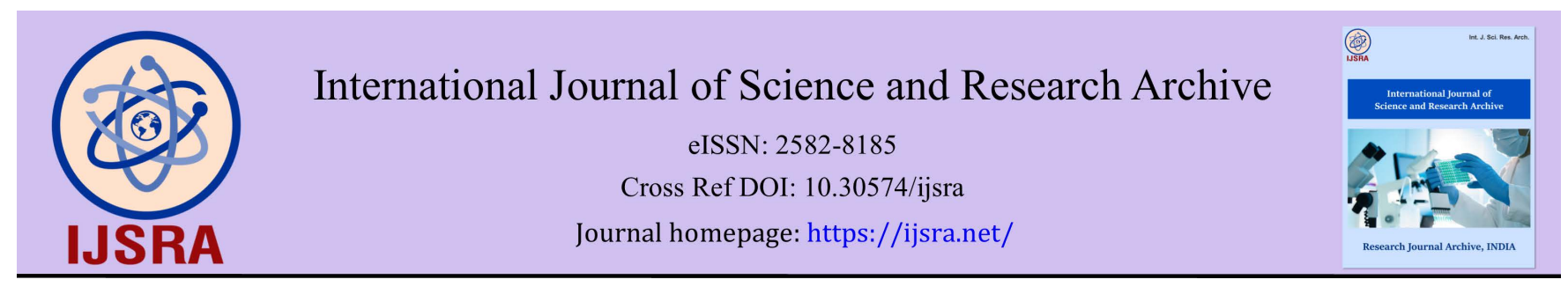

(RESEARCh ARTicle)

\title{
Serum ferritin levels as an early prognostic marker in dengue fever
}

\author{
Ravi Prakash 1, Sujata Agarwal 2, Radhey Shyam Chejara 2, Pradeep Mital 2, *, Suresh Yadav 2 and Shashi \\ Bhushan Sharma ${ }^{2}$
}

${ }^{1}$ Rajasthan University of Health Sciences, Jaipur.

2 S.M.S. Medical College, Jaipur.

International Journal of Science and Research Archive, 2022, 05(01), 073-078

Publication history: Received on 01 January 2022; revised on 06 February 2022; accepted on 08 February 2022

Article DOI: https://doi.org/10.30574/ijsra.2022.5.1.0041

\begin{abstract}
Dengue virus infection is showing upsurge with rapid urbanization and climate change in India. The spectrum of disease varies from mild illness to severe disease such as dengue hemorrhagic syndrome, dengue shock, multi-organ failure, and death therefore prompt recognition of severe form is crucial to improve the survival in severe dengue. Currently there are no tests available to predict the course of the illness therefore it is imperative to develop an early reliable and feasible biomarker to predict the severity of dengue illness which can aid in vigorous monitoring and early intervention. In this study we tried to establish a correlation between serum ferritin and severity of dengue illness and analyzed whether serum ferritin can be used to predict the severity at an earlier stage.
\end{abstract}

Methods: This was a Cross sectional study conducted at tertiary care hospital. 350 patients above 18 years with fever of duration less than 2 weeks with thrombocytopenia were enrolled. Serum ferritin levels were measured and results were analyzed.

Results: Out of 350 patients Dengue was diagnosed in 210 patients. Mean Ferritn levels were highest in dengue patients $(2898.18 \pm 2097.72 \mu \mathrm{g} / \mathrm{l})$ and Severe dengue patients had significantly higher median ferritin levels (3985 $\mu \mathrm{g} / \mathrm{l})$ compared to non-severe dengue group with median $1936 \mu \mathrm{g} / \mathrm{l}(\mathrm{p}$ value $<0.001)$.

Conclusion: Serum ferritin can serve as a surrogate marker of dengue fever. Serum ferritin is an inexpensive and easily accessible biomarker that can be used as a prognostic marker to predict severity of disease.

Keywords: Dengue; Arthropod borne; Ferritin; Disease severity; Prognostic marker

\section{Introduction}

Dengue fever is the arthropod-borne viral illness caused by Arbovirus of Flavivirus genus with 4 serotypes and highly prevalent in tropical and subtropical areas $[1,2] .3 .97$ billion people across 128 endemic countries including India are currently at risk for dengue infection [3]. Transmission occurs by Aedes aegypti and Aedes albopictus mosquitoes [3]. The spectrum of illness ranges from mild fever to severe forms of dengue fever like dengue hemorrhagic fever and dengue shock syndrome [4]. Dengue fever presents as acute febrile illness of 2-7 days with headache, retroorbital pain, myalgia, arthralgia, rash, and hemorrhagic manifestations [5]. In clinical practice, patients with dengue infection are grouped as 1) severe disease: those with warning signs that need intensive monitoring and aggressive management 2) non-severe disease: those without warning signs [6].

\footnotetext{
* Corresponding author: Pradeep Mital

S.M.S. Medical College, Jaipur.

Copyright $(2022$ Author(s) retain the copyright of this article. This article is published under the terms of the Creative Commons Attribution Liscense 4.0.
} 
Dengue fever is diagnosed by NS1 antigen reactivity by ELISA usually in the first 5 days of fever and after that by IgM detection by MAC-ELISA. IgM appears usually within 5-7 days of fever but sometimes it may take more time, even more than 10 days [7]. The sensitivity of NS1 for diagnosis is more than $90 \%$ within $2-3$ days of illness after that sensitivity gradually decreases [8]. High levels of AST, ALT, LDH, CK, and prolonged aPTT are significant predictors of mortality in patients of fever with thrombocytopenia. However, there is a need for surrogate markers to differentiate between various etiologies of febrile thrombocytopenia like dengue and other viral fevers, malaria, scrub typhus, viral hepatitis, enteric fever, LRTI, bacterial sepsis [8].

Ferritin is an iron-binding molecule that stores iron in a biologically available form for vital cellular processes while protecting proteins, lipids and DNA from the potential toxicity of this metal element. Ferritin plays a role in a large number of other conditions, including inflammatory, neurodegenerative and malignant diseases [9]. Some studies have suggested that serum ferritin can serve as a surrogate marker of febrile thrombocytopenia triggered by viral infections such as dengue fever [7,10]. Hyperferritinemia in dengue virus infected patients is indicator of highly active disease which results in immune activation and coagulation disturbances so requires intense monitoring [11,12]. However still there is dearth of evidence correlating serum ferritin with severity of dengue infection so this study was done to find association of Serum ferritin level with severity of dengue infection.

\section{Material and methods}

This was a cross sectional study conducted in the Department of Medicine of tertiary care hospital. All new hospitalized patients above 18 years with fever (temperature $>99.9^{\circ} \mathrm{F}$ ) and fever duration less than 2 weeks with thrombocytopenia (platelet count $<1,30,000$ cells/mm3) \& those willing to participate in study, were enrolled after obtaining written informed consent. Patients presenting with thrombocytopenia without fever, immune thrombocytopenic purpura, on treatment with antiplatelet drugs and other drugs causing thrombocytopenia, chronic liver disease were excluded. The serum ferritn levels were measured by chemiluminescent enzyme immunoassay system using the Clinical Analy Adeva Centour XP. Data were entered in MS excel sheet and statistically analyzed. P value less than 0.05 was considered as statistically significant.

\section{Results}

Out of 350 patients of fever, 210 patients (60\%) were diagnosed to have dengue infection. Chikungunya was diagnosed in $10.3 \%$, scrub typhus in 6\%, malaria in $5.4 \%$, viral hepatitis in $4.6 \%$ and sepsis in $13.7 \%$ cases. (Table 1 ).

Table 1 Distribution of the Patients According to Various Etiologies

\begin{tabular}{|l|c|c|}
\hline Etiology & No. of patients & Percentage \\
\hline Dengue & 210 & 60.0 \\
\hline Sepsis & 48 & 13.7 \\
\hline Chikungunya & 36 & 10.3 \\
\hline Scrub typhus & 21 & 6.0 \\
\hline Malaria & 19 & 5.4 \\
\hline Viral hepatitis & 16 & 4.6 \\
\hline
\end{tabular}

S. Ferritin level in dengue patients (mean 2898.2 $\pm 2097.7 \mu \mathrm{g} / \mathrm{l}$, median $2308 \mu \mathrm{g} / \mathrm{l}$, IQR1755.75- $3656 \mu \mathrm{g} / \mathrm{l}$ ) was significantly higher as compared to sepsis (mean 619.4 $\pm 335.4 \mu \mathrm{g} / \mathrm{l}$, median $561 \mu \mathrm{g} / \mathrm{l}, \mathrm{IQR}$ 416.5-811.5 $\mu \mathrm{g} / \mathrm{l}$ ), chikungunya (mean 1059.1 $\pm 627.8 \mu \mathrm{g} / \mathrm{l}$, median $911.5 \mu \mathrm{g} / \mathrm{l}$, IQR $824.9-1246.6 \mu \mathrm{g} / \mathrm{l}$ ), scrub typhus (mean $997.1 \pm 496.8$ $\mu \mathrm{g} / \mathrm{l}$, median $834 \mu \mathrm{g} / \mathrm{l}$, IQR 812.75-1390.5 $\mu \mathrm{g} / \mathrm{l}$ ), malaria patients (mean 339.3 $125.2 \mu \mathrm{g} / \mathrm{l}$, median $317 \mu \mathrm{g} / \mathrm{l}$, IQR (68$368 \mu \mathrm{g} / \mathrm{l}$ ) and viral hepatitis (mean $800.10 \mu \mathrm{g} / \mathrm{l}$, median $740 \mu \mathrm{g} / \mathrm{l}$, IQR 571-999.5 $\mu \mathrm{g} / \mathrm{l}$ ) with p value < 0.001. (Table 2) 
Table 2 Mean Serum Ferritin Level $(\mu \mathrm{g} / \mathrm{l})$ in various infections

\begin{tabular}{|l|c|c|c|}
\hline Etiology & Mean Serum Ferritin & Median (Interquartile range) & P value \\
\hline Dengue & $2898.2 \pm 2097.7$ & $2308(1755.8-3656)$ & \\
\cline { 1 - 3 } Sepsis & $619.4 \pm 335.4$ & $561(416.5-811.5)$ & \\
\cline { 1 - 3 } Chikungunya & $1059.1 \pm 627.8$ & $911.5(824.9-1246.6)$ & \multirow{2}{*}{0.001} \\
\cline { 1 - 3 } Scrub typhus & $997.1 \pm 496.8$ & $834(812.75-1390.5)$ & \\
\cline { 1 - 4 } Malaria & $339.3 \pm 125.2$ & $317(268.0-368.0)$ & \\
\cline { 1 - 3 } Viral hepatitis & $676.2 \pm 391.1$ & $616.2(592.8-712.1)$ & \\
\hline
\end{tabular}

Among 210 dengue patients, 133 are diagnosed to have severe dengue and 77 as non-severe dengue according to WHO 2009 classification. Serum ferritin levels in severe and non-severe dengue are compared using Mann Whitney U test. Severe dengue patients had higher median ferritin levels (3985 $\mu \mathrm{g} / \mathrm{l} \& \mathrm{IQR} 2007 \mu \mathrm{g} / \mathrm{l})$ compared to non-severe dengue group (median $1936 \mu \mathrm{g} / \mathrm{l} \& \mathrm{IQR} 1940 \mu \mathrm{g} / \mathrm{l}$ ). A statistically significant difference was observed in ferritin levels between the severe \& non severe dengue groups $(\mathrm{P}<0.001)$. (Table 3$)$

Table 3 Comparison of Serum Ferritin in Severe and Non-Severe Dengue

\begin{tabular}{|l|l|c|c|c|}
\hline Marker & Severity of Dengue & Median & Inter Quartile Range & P value \\
\hline \multirow{2}{*}{ Ferritin } & Severe (133) & 3985 & 2007 & \multirow{2}{*}{$<0.001$} \\
\cline { 2 - 5 } & Non Severe (77) & 1936 & 1940 & \\
\hline
\end{tabular}

Table 4 and Figure 1 show Pearson correlation between S. Ferritin and platelet counts in dengue patients. It indicates that there is a significant very small negative relation between $\mathrm{S}$. Ferritin and platelet counts, $\mathrm{r}=-0.4255, \mathrm{p}<0.001$.

Table 4 Correlation of Serum Ferritin Levels and Platelet Count in dengue infection $(n=210)$

\begin{tabular}{|l|c|l|l|}
\hline Parameters & Mean \pm SD & R & P value \\
\cline { 1 - 2 } S. Ferritin & $2874.47 \pm 2102.43$ & \multirow{2}{*}{-0.4255} & $<0.001$ \\
\cline { 1 - 2 } Platelet count & $28438.1 \pm 18073.71$ & & \\
\hline
\end{tabular}

\section{Discussion}

In the present study dengue with 210 cases was the leading cause of fever associated with thrombocytopenia and second common cause was septicaemia with 48 cases. This was followed by chikungunya (36 cases), Scrub typhus (21 cases). Dengue and chikungunya were the common cause due to the higher prevelance of these infections during the perimonsoon period. Our results were similar to that observed by Gondhali et al [13]. They found that Dengue with 56 cases was leading cause of fever associated with thrombocytopenia. Second common cause was septicaemia (17 cases) followed by Malaria (15 cases). Our results were in contrast to that observed by Nair PS et al where septicaemia with 29 cases was the leading cause of fever associated with thrombocytopenia. Second common cause was enteric fever (16 cases) followed by dengue (15 cases) and malaria (10 cases) [14]. Lohitashwa et al in their study found that malaria with 41 cases was the leading cause of fever associated with thrombocytopenia followed by septicaemia and dengue with $24 \& 19$ cases respectively [15].

Mean and median ferritin levels (mean $2898.2 \pm 2097.7 \mu \mathrm{g} / \mathrm{l}$, median $2308 \mu \mathrm{g} / \mathrm{l}$ ) in our study was higher than mean and median ferritin levels (mean $1399.53 \mu \mathrm{g} / \mathrm{l}$, median $1856 \mu \mathrm{g} / \mathrm{l}$ ) observed in the study done by Petchiappan $\mathrm{V}$ et al [6]. S. Ferritin level in dengue patients (mean 2898.2 $\pm 2097.7 \mu \mathrm{g} / \mathrm{l}$, median $2308 \mu \mathrm{g} / \mathrm{l}$, IQR 1755.75 - $3656 \mu \mathrm{g} / \mathrm{l}$ ) was significantly higher as compared to other infective etiology $(\mathrm{p}<0.001)$. Our results were in line with that observed by Chaudhuri SR et al [16]. They observed a higher ferritin level in dengue cohort (median $2745 \mu \mathrm{g} / \mathrm{l} \&$ IQR $1574-3452$ 
$\mu \mathrm{g} / \mathrm{l}$ ) than in other febrile illness cohort (median 344.15 $\mu \mathrm{g} / \mathrm{l} \& \mathrm{IQR} 157-815.2 \mu \mathrm{g} / \mathrm{l}$ ). Similarly in the studies conducted by Soundravally $\mathrm{R}$ et al [7] and van de Weg CAM et al [11] compared to other febrile illnesses, dengue cases demonstrated significant increase in serum ferritin levels.

In our study severe dengue patients had significant higher median ferritin levels (3985 $\mu \mathrm{g} / \mathrm{l} \& \mathrm{IQR} 2007 \mu \mathrm{g} / \mathrm{l})$ compared to non-severe dengue group (median $1936 \mu \mathrm{g} / \mathrm{l} \& \mathrm{IQR} 1940 \mu \mathrm{g} / \mathrm{l})(\mathrm{p}<0.001)$. This is in line with similar study by Diwakar TN \& Madhu G, where significant association was found between raised serum ferritin levels and severe dengue ( $p<0.001$ ) [17]. Petchiappan V et al [6] and Soundravally R et al [7] in their studies showed that hyperferritinemia is assosciated with severe dengue and that serum ferritin levels can predict the severity of dengue at an earlier stage.

In the present study serum ferritin and platelet count in dengue patients showed inverse correlation $(r=-0.4255, \mathrm{p}$ value $<0.001$ ) that is decrease in platelet counts in these patients is associated with proportional increase in ferritin levels. Our results are similar to observation made by Petchiappan V et al [6]. They also observed a significant negative correlation between serum ferritin levels and platelet count ( $P$ value $<0.001$ ). Similarly Khubchandani A et al in their study also observed that high serum ferritin level significantly associated with thrombocytopenia ( $p$ value $<0.001)$ [18]. $\mathrm{S} J$ Visalakshy et al in their study also showed a negative correlation which was however not statistically significant $(\mathrm{r}=-$ $0.243, \mathrm{p}=0.231$ ) [19].

Ferritin is an acute-phase reactant and highly expressed by cells of the reticulo-endothelial system in response to inflammation and infection [11]. So a modest rise in ferritin levels is expected in all infective conditions whether viral, bacterial or parasitic in nature. Ferritin is highly elevated in dengue infected patients than in patients with other febrile illnesses [11]. Studies in the past have shown that ferritin may serve as an important marker for differentiating between dengue fever and other febrile illnesses of infective or inflammatory cause, in the absence of a positive NS1antigen [18]. Macrophages, lymphocytes and monocytes are the major target cells of dengue virus replication in vivo [11,18]. The important producers of ferritin are monocyte, macrophages and hepatocytes, and therefore direct infection and subsequent viral replication in these cells may activate them and increase the ferritin production [18]. Thrombocytopenia is a hallmark of dengue virus infection and one of the indicators for the clinical severity of the disease [20]. It is postulated that thrombocytopenia can be caused by suppression of the bone marrow, increase consumption and increase destruction due to increase apoptosis, lysis by the complement system and involvement of antiplatelet antibodies [21,22]. A Khubchandani et al in their study observed that the platelet count was significantly decreased in patients with hyperferritinaemia compared to patients with no hyperferritinaemia so ferritin may serve as a potential biomarker for an early prediction of dengue severity [18]. Estimation of S. Ferritin during the critical period of febrile illness in which clinicians are in the phase of diagnostic dilemma can aid in the clinical judgment \& diagnosis so that prompt and early life saving measures can be implemented.

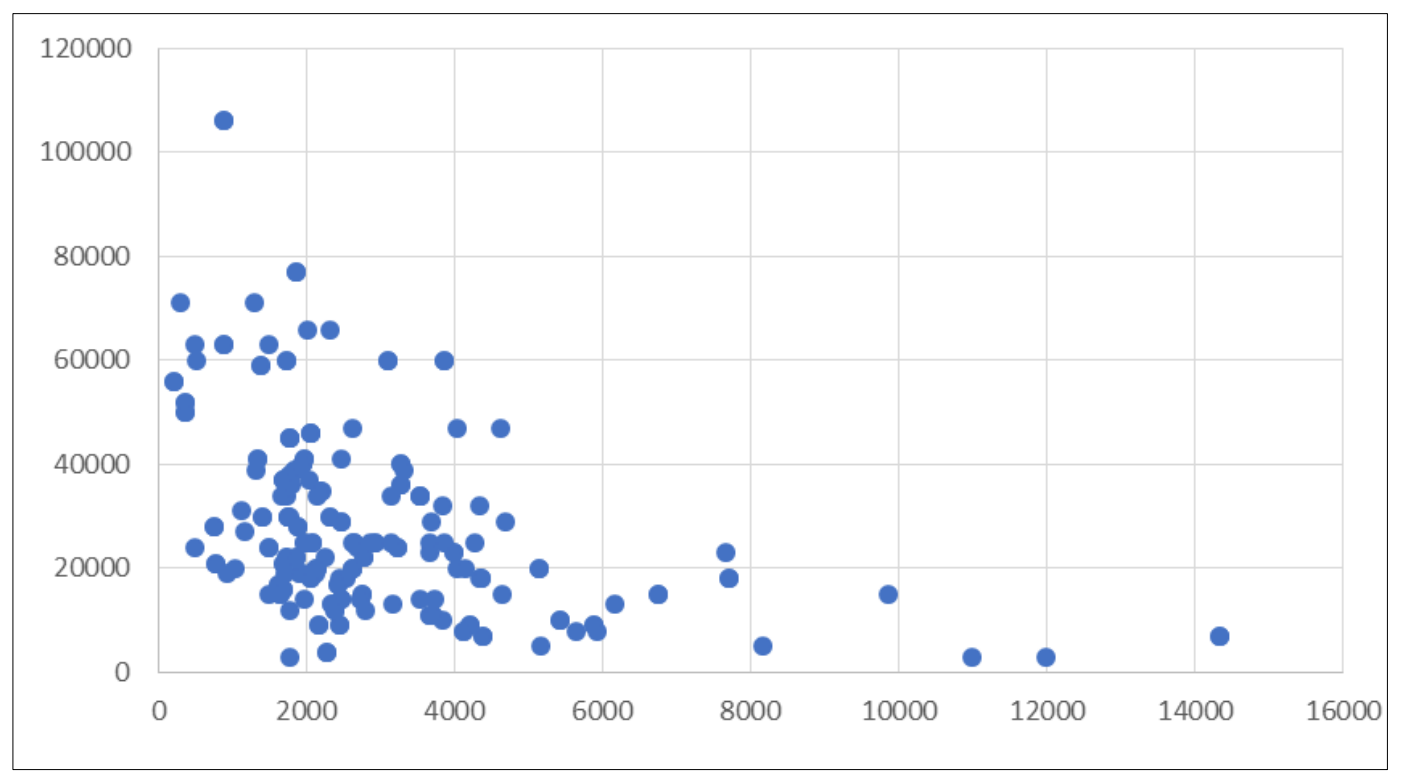

Figure 1 Correlation of Serum Ferritin Levels (X axis) and Platelet Count (Y axis) in dengue infection (n=210) 


\section{Conclusion}

We observed significant higher ferritin levels in dengue fever compared to other etiologies of febrile thrombocytopenia as well as significantly higher levels in severe dengue disease than in non-severe disease. Serum ferritin can be used as a surrogate marker for dengue infection (especially in NS1ag and IgM negative stage) and to predict the severity of dengue fever infection.

\section{Compliance with ethical standards}

\section{Acknowledgments}

We would like to thank all the participants who volunteered for this study. We also express our thanks to Dr Sadanand Dagar, Dr Subhash Bijraniya and Dr Suraj for their help in this study.

\section{Disclosure of conflict of interest}

None

\section{Statement of informed consent}

Informed consent was obtained from all individual participants included in the study.

\section{References}

[1] SA Abubakar, N Shafee. "Outlook of dengue in Malaysia: a century later," The Malaysian Journal of Pathology. 2002; 24(1): 23-27.

[2] OJ Brady, PW Gething, S Bhatt et al., "Refining the global spatial limits of dengue virus transmission by evidencebased consensus," PLoS Neglected Tropical Diseases. 2012; 6(8): Article ID e1760.

[3] V Duong, L Lambrechts, RE Paul et al. “Asymptomatic humans transmit dengue virus to mosquitoes," Proceedings of the National Academy of Sciences. 2015; 112(47): 14688-14693.

[4] World Health Organization (WHO) and the Special Programme for Research and Training in Tropical Diseases (TDR). Dengue guidelines for diagnosis, treatment, prevention and control. 2009.

[5] National Guidelines for Clinical Management of Dengue Fever, National Vector Bourne Disease Control Programme. 2015, http://www.nvbdcp.gov.in/Doc/Clinical\%20Guidelines.pdf.

[6] Petchiappan V. Hussain MT., Thangavelu S. Can serum ferritin levels predict the severity of dengue early? An observational study. Int J Res Med Sci. 2019; 7(3): 876-881.

[7] R Soundravally, B Agieshkumar, M Daisy, J Sherin, CC Cleetus. "Ferritin levels predict severe dengue," Infection. 2015; 43(1): 13-19.

[8] Laboratory Guidance and Diagnostic Testing-Dengue-CDC. 2017.

[9] Muller DA, Depelsenaire AC, Young PR. Clinical and Laboratory Diagnosis of Dengue Virus Infection. J Infect Dis. 1 Mar 2017; 215(2): S89-S95.

[10] World Health Organization, "Prevention and Control. 2009; 409(3): 160, http://apps.who.int/iris/handle/10665/44188.

[11] van de Weg CAM, Huits RM, Pannuti CS, Brouns RM, van den Berg RW, van den Ham HJ, Martina BE, Osterhaus AD, Netea MG, Meijers JC, van Gorp EC, Kallas EG. Hyperferritinaemia in dengue virus infected patients is associated with immune activation and coagulation disturbances. PLoS Negl Trop Dis. 9 Oct 2014; 8(10): e3214.

[12] Ho, T Wang S, Anderson R, Liu C. "Antibodies in dengue immunopathogenesis," Journal of the Formosan Medical Association. 2013; 112(1): 1-2.

[13] Gondhali MP, Vethekar M, Bhangale D, Choudhary K, Chaudhary M, Patrike G, Kundgir A. International. Clinical assessment of fever with thrombocytopenia - A prospective study. Journal of Medical Research \&Health Sciences. 2016; 5(1): 258-77. 
[14] Nair PS, Jain A, Khanduri U, Kumar V. "A study of fever associative with Thrombocytopenia”. JAPI, Dec 2003- 51: 1151-73.

[15] Lohitashwa SB, Vishwanath BM, Srinivas G. A Study of Clinical and Lab Profile of Fever withT hrombocytopenia. 2009 JAPI March; 57.

[16] Choudhari SR, Bhattacharya S, Chakraborty M, Bhattacharjee K. Serum Ferritin: A Backstage Weapon in Diagnosis of Dengue Fever. Interdisciplinary Perspectives on Infectious Diseases. Oct 2017; 1-6. Article ID 7463489

[17] Diwakar TN, Madhu G. Role of Serum Ferritin and Serum Aminotransferases in Predicting the Severity in Dengue Fever with Thrombocytopenia. J. Evolution Med. Dent. Sci. 2018;7(50):5378-5382, DOI: $10.14260 /$ jemds/2018/1190

[18] Khubchandani A, Patel V, Gajjar D, Prajapati B. Role of serum ferritin in dengue and its correlation with disease severity. BJKines-NJBAS. 2020; 12(2): 58-62.

[19] Visalakshy SJ, Saminathan SS, Surendran S, Pillai M G. Hyperferritinemia in Dengue fever Correlation between serum Ferritin and Thrombocytopenia. Journal of Clinical and Diagnostic Research. April 2018; 12(4): OC07OC09.

[20] Kalayanarooj S. Dengue classification: current WHO vs. the newly suggested classification for better clinical application? J Med Assoc Thai. 2011; 94(3): S74-84. PMID: 22043757

[21] Castilho BM, Silva MT, Freitas ARR, et al. Factors associated with thrombocytopenia in patients with dengue fever: a retrospective cohort study. BMJ Open. 2020; Sep 13;10(9):e035120. doi: 10.1136/bmjopen-2019035120. PMID: 32928847; PMCID: PMC7488788.

[22] De Azeredo EL, Monteiro RQ, de-Oliveira Pinto LM. Thrombocytopenia in dengue: interrelationship between virus and the imbalance between coagulation and fibrinolysis and inflammatory mediators. Mediators Inflamm. 2015;2015:313842. doi: 10.1155/2015/313842. Epub 2015 Apr 27. PMID: 25999666; PMCID: PMC4427128. 